\title{
ASSESSMENT OF THE LAND SURFACE TEMPERATURE DYNAMICS IN THE CITY OF SOFIA USING LANDSAT SATELLITE DATA
}

\author{
Ivan Yanev ${ }^{1}$, Lachezar Filchev ${ }^{2}$ \\ ${ }^{1}$ ESRI Bulgaria Ltd. \\ ${ }^{2}$ Space Research and Technology Institute - Bulgarian Academy of Sciences \\ e-mail: ivan.yanevmail@gmail.com
}

\begin{abstract}
The article presents the first attempt to analyse the urban heat island of the city of Sofia using satellite data. For this purpose the thermal data from Landsat ETM+ and TIRS sensors have been used. A statistical analysis of the results was carried out as well as an analysis of the changes in the surface temperature for the selected time interval - 2000-2015. The impact of the type of land cover was analyzed. For this purpose, a visual land-cover classification has been drawn up, whereby the surveyed territory is divided into 16 classes. A detailed analysis of the data over the entire survey period shows a gradual rise in the city's temperature due to the change in the urban environment. One of the conclusions of the stury is that thermal images over time can be successfully used to detect changes in the land cover by temporal analysis.
\end{abstract}

\section{Introduction}

With the advent of the first satellites equipped with sensors in the thermal range of the electromagnetic spectrum in the early 1970s, the Earth's surface temperature began to be investigated also by remote sensing means. The possibility of urban areas being identified by thermal data obtained from a satellite was first demonstrated by [1, 2]. In this study the authors used data from the SR (Scanning Radiometer) satellite sensor ITOS-1 (Improved TIROS Operational Satellite). Then, with the commissioning of new thermal sensors worn by various satellite platforms, a more in-depth study of the city's thermal island began through satellite data.

One of the pioneers to explore urban heat islands by remote sensing methods are [2, 3-8]. While [1] attempted to roughly outline the boundaries of cities, Matson et al. (1978) uses thermal data $(10.5 \div 12.5 \mu \mathrm{m})$ from the NOAA Very High Resolution Radiometer (VHRR), recorded overnight, to investigate differences in temperature on urban and non-urban surfaces; [5] uses data $(10.5 \div 12.5 \mu \mathrm{m})$ from the Heat Capacity Mapping Mission (HCMM) to estimate the spatial coverage and intensity of urban surface warming. Later on [7] use 
Advanced High Resolution Radiometer (AVHRR) thermal data to assess the intensity of the city's thermal islands in three coastal cities in North America.

Although the Landsat 5 Thematic Mapper (TM) mission started in 1984, we do not have data for research using TM sensor data over the next few years of satellite operation. The graphs presented above for the number of articles per year show that only in 1990 there were more research, with a major part based on Landsat 5 TM. Authors such as [9] evaluate the feasibility of the thermal band of the TM, which hass $120 \mathrm{~m}$ spatial resolution, to classify terrain in urban environments. The team [10] investigated the model of surface temperature in Tokyo, and [11] the impact of the urbanization process on the formation of thermal islands. The so-called "heat sinks" and the effect of green areas in the city have been analysed for the first time by $[8,12]$. The thermal radiation of various discrete surfaces were studied by [13], and [14] map the formation of micro-UHI.

\section{Study area}

The area of interest is the city if Sofia - the capital and the biggest city of Bulgaria, and the $16^{\text {th }}$ largest city in the EU [15]. It is located in the West part of

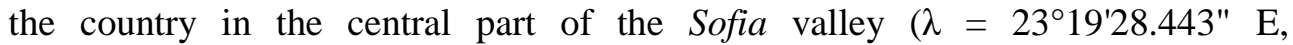
$\varphi=42^{\circ} 41^{\prime} 48.492^{\prime \prime} N$ ) which in turn extends from North-West to South-East between Balkan Mountains on the North and the mountains Viskyar, Lyulin, Vitosha, Lozenska on the South, the rivers Slivnishka and Gaberska on the West and to the East it borders with Vakarel Mountain. The entire character of the landscape defines the climate of Sofia. According to climate classification adopted in Bulgaria, Sofia falls into temperate continental climate subzone of European continental climate zone [16].

The city of Sofia is constantly growing in population. The official population estimate in 2015 is around 1.3 million people (2011 census) [17].

\section{Materials and Methods}

\section{Satellite data}

Considering the timeframe of the study, we have used data from Landsat ETM+ and Landsat TIRS. Both sensors allow acquisition in the thermal range. Given the fact that the former has one thermal band and the second one two, a different approach to image processing should be used. According to official information about Landsat 8 the mission (URL: http://landsat.usgs.gov/ Landsat8_Using_Product.php), however, thermal bands 10 and 11 are affected by heat outside the range of the normal field of view called stray light. Band 11 is significantly more affected then Band 10, so it is recommended that users refrain from using Band 11 in split-window LST extraction algorithms. For this reason, only Band 10 is used on Landsat 8. Below, we will look at various processing 
methods for both sources. The Landsat data used is level $1 \mathrm{~T}$ imagery downloaded from URL: http://earthexplorer.usgs.gov/, as well as Landsat Higher Level Science Product Product downloaded from URL: http://espa.cr.usgs.gov/. Both products use the original, unprocessed Level 1 product as original data and are radiometrically and geometrically corrected, with a $30 \mathrm{~m}$ spatial resolution in the thermal range (resized from $60 \mathrm{~m}$ ETM+ and $100 \mathrm{~m}$ TIRS), Universal Transverse Mercator (UTM), World Geodetic System (WGS) 84 and GeoTIFF (URL: http://landsat.usgs.gov/Landsat_Processing_Details.php). The higher-level product contains most of the images since 1982 and includes reflection and brightness data recorded by the sensor (Top of Atmosphere Reflectance and Brightness Temperature), Surface Reflectance and related indexes, such as Normalized Difference Vegetation Index (NDVI), etc., as well as Cloud Mask. In addition, images can be downloaded in a different format, coordinate system, spatial range, and pixel size. It is planned to have a ready LST product in the future. Some of the available Landsat images were dropped out of the analysis for a variety of reasons - cloud cover, missing product data of higher level, or missing data on atmospheric parameters. Therefore, only valid images totaling $35-6$ images from Landsat 8 between 2013 and 2015 and 29 images from Landsat 7 from 2000 to 2015 - were included in the analysis. After a careful review of all the images, a difference in quality of images. In spite of the lower spatial resolution, the Landsat 8 images are much more pronounced than the thermal island in the city, while those from Landsat 7 appear to be slightly fuzzy, possibly due to the fact that Landsat 8 has almost twice the dynamic range -12 bits against 8 bits for Landsat 7 . This means that the first sensor records 4096 shades while the second only 256 shades of gray. However, both types of data require a very careful selection of the color scheme of the images in order to best visualize the temperature differences.

\section{Meteorological data}

We have used meteorological data provided by National Institute of Meteorology and Hydrology (NIMH-BAS) in order to evaluate the accuracy of the derived temperature values. For the date of each image, we have three ground measurements of the land surface temperature at 7, 14 and $21 \mathrm{~h}$ local time. Since Landsat's daytime images are captured at about $12 \mathrm{~h}$ local time, and at night around $23 \mathrm{~h}$, we used the values of 14 and $21 \mathrm{~h}$ for validation of LST extraction methods.

\section{Satellite data processing}

The first step in the processing of thermal satellite images is the conversion of pixel values into at-sensor spectral radiance. The conversion is done by the following formula:

1) $L_{\lambda}=M_{L} * D N+A_{L}$, 
where: $\mathrm{L}_{-} \lambda$ is the spectral emmission registered at sensor (Watts/( $\left.\mathrm{m}^{2} * \operatorname{srad} * \mu \mathrm{m}\right) ; \mathrm{M} \_\mathrm{L}$ is a multiplicative scale factor from the methadata (REFLECTANCE_MULT_BAND_x, where $\mathrm{x}$ is the band number); A_L is an additive scale factor from the methadata (REFLECTANCE_ADD_BAND_x, where $\mathrm{x}$ is band number).

It is clear that each type of earth land cover has a different emissivity that is influenced by the instant physical state of the object. Therefore, it is important that the value of $\varepsilon$ is measured at the time of the satellite platform's passage for each individual image. Because we do not have such field measurements, we need to use one of the methods to calculate this parameter. An average value (based on published measurements or spectral libraries) for each type of land surface is assigned to the classification method, but the current state of the site may not be taken into account. Therefore, we decide to use the method using NDVI (taken from the Landsat product), where the values for one type of land cover can vary depending on the time of data acquisition. We use threshold values for NDVI as follows:

If NDVI $<0.2$ type of land cover is considered soil, and $\varepsilon=0.97$;

If NDVI>0.5 type of land cover is considered vegetation, and $\varepsilon=0.99$;

If $0.2 \leq \mathrm{NDVI} \geq 0.5$ type of land cover is considered mixed,

2) $\varepsilon=m P_{v}+n$,

where:

$\mathrm{P} \_\mathrm{v}$ is vegetation proportion,

3)

$$
\begin{aligned}
& P_{v}=\left[\frac{N D V I-N D V I_{\text {min }}}{N D V I_{\max }-N D V I_{\min }}\right]^{2} \\
& m=\varepsilon_{v}-\varepsilon_{s}-\left(1-\varepsilon_{s}\right) F \varepsilon_{v}, \\
& n=\varepsilon_{s}+\left(1-\varepsilon_{s}\right) F \varepsilon_{v},
\end{aligned}
$$

where:

$\varepsilon_{v}$ is vegetation emmissivity,

$\varepsilon_{S}$ is soil emissivity,

$F$ is a geometry factor $=0.55$, therefore the final equation for $\varepsilon$ (at NDVI between 0.2 and 0.5 ) is:

4)

$$
\varepsilon=0.004 P_{v}+0.986
$$

We have used two methods for calculating surface radiance the radiative transfer equation (RTE) and Jimenez-Munoz and Sobrino (SC) Single-Channel 
Algorithm [18]. Transformation of the surface emissivity into surface temperature for LST retrieval from thermal images is to convert the resulting surface radiance value to a LST.

$$
\text { 5) } \quad T=\frac{K_{2}}{\ln \left(\frac{K_{1}}{L_{\lambda}}+1\right)}
$$

where: $K_{1}=c_{1} / \lambda^{5}, K_{2}=c_{2} / \lambda$, including $c_{1}$ and $c_{2}$, which are $1^{\text {st }}$ and $2^{\text {nd }}$ radiation constants, and $\lambda$ is effective wavelength.

Table 1. $K_{1}$ and $K_{2}$ values for Landsat 7 and Landsat 8 thermal bands

\begin{tabular}{|c|c|c|}
\hline & L7B6 & L8B10 \\
\hline $\mathbf{K}_{\mathbf{1}}$ & 666.09 & 774.89 \\
\hline $\mathbf{K}_{\mathbf{2}}$ & 1282.71 & 1321.08 \\
\hline
\end{tabular}

\section{Results and Discussions}

Here we present a brief visual analysis of the obtained images and in the following paragraphs we will analyze in more detail the influence of the type of land cover, the changes in the land cover, the change and the dynamics of the surface temperature.

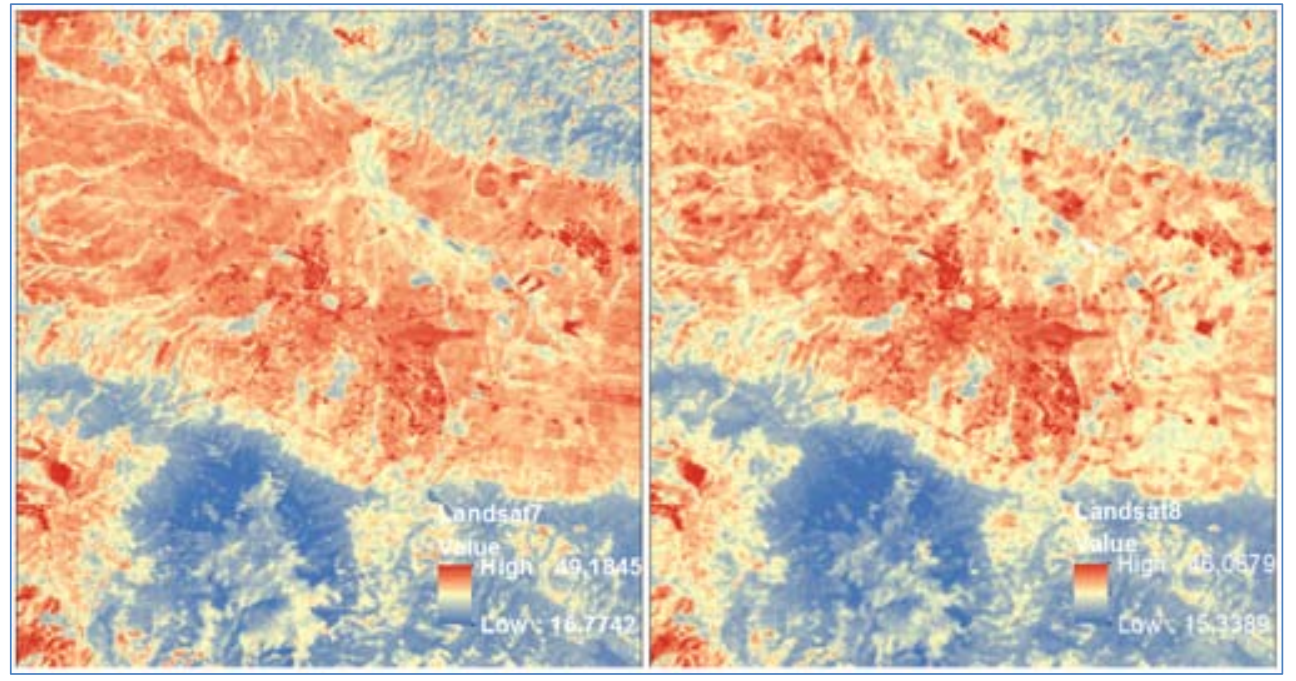

Fig. 1. Average of all images used in the analysis for Landsat 7 (left) and Landsat 8 (right) 
On Fig.1 is depicted the influence of the city on the LST. At first glance, several characteristic areas with particularly elevated temperature values in the range of $35 \div 45{ }^{\circ} \mathrm{C}$ stand out. These are the districts around Sofia Airport and to the south of it in the Druzhba neighborhood, the Center quarter, as well as in the northwestern part of the Nadezhda district. The high temperature of the whole valley of Sofia is also clearly visible, compared to the surrounding mountains of Stara Planina in North and Vitosha in the South. During the summer months, the bare and dry soil has values close to those on the impermeable surfaces of the city. This is evidenced by the increase in temperature on the mountain ridges. In addition to elevated temperatures, however, the outlines of larger parks such as South Park and West Park, which values are significantly lower - about $23 \div 24{ }^{\circ} \mathrm{C}$, are clearly visible. A cool strip along the Iskar River valley also stands out. As we observe the temperatures for a period of 15 years, it is especially interesting to see if and in which direction the LST values are developing. For this purpose, we divided the images into three intervals - from 2000 to 2005, 2006-2010 and 2011-2015. Thus, the images are divided in the first interval of four images, and in the next two 12 and 19 respectively.

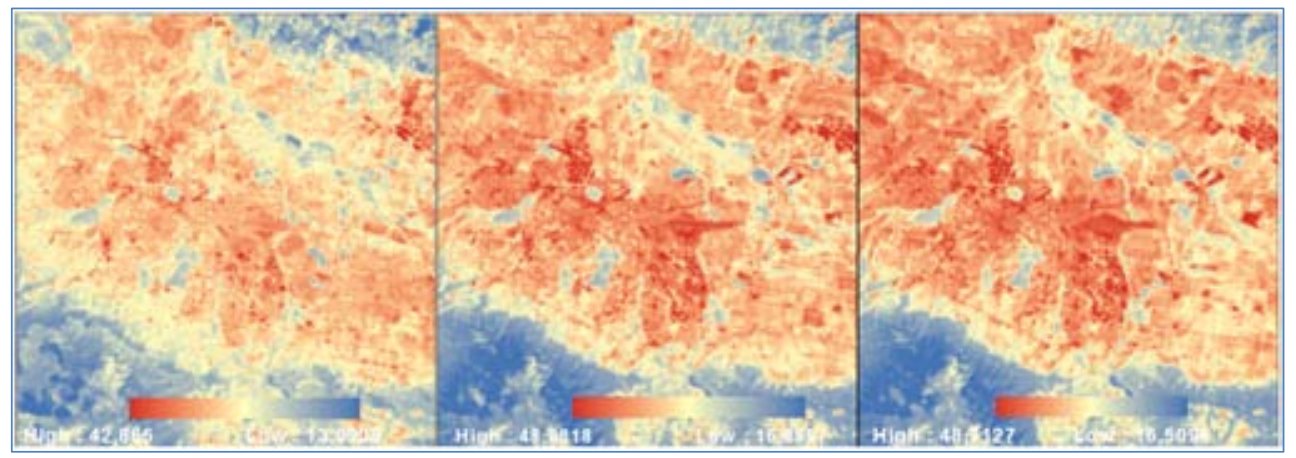

Fig. 2. LST averaged over three time intervals: 2000-2005, 2006-2010, and 2011-2015 (left to right)

The tendency for a gradual increase in reddish areas in images is seen, and this is much more noticeable between the first two intervals. When carefully examining the images on the appropriate scale, a saturation at each of the temperature ranges is noticed. Once a tendency for surface temperature increase is observed at these intervals, it is necessary to follow the heat stroke a little in detail. For this purpose, we have devoted one image to each of the years which we have, giving priority to the dates around and after mid-July. This gave us a total of 13 images under the most similar acquisition conditions, which we averaged in proportions in five consecutive acquisitions with a displacement of each proportion in a single forward, i.e. if P1 covers the interval between 2000 and 2004, then 
P2 = P1 + 1 or from 2001 to 2005, etc. Thus, a total of 9 five-year averaged images were obtained.

The different methods of data averaging have a significant impact on the absolute values of the surface temperature. In the first "Method 1", within the selected timeframe, all the available images in the database are determined by the image selection criteria. The second "Method 2" includes selected images captured under the most similar conditions during the warmest and driest period of the year. This leads to an increase in surface temperature and a distinct manifestation of the urban heat island. In the following Fig. 4, the visualization of the UHI for the period 2011-2015 can be visually compared to the two averaging methods.
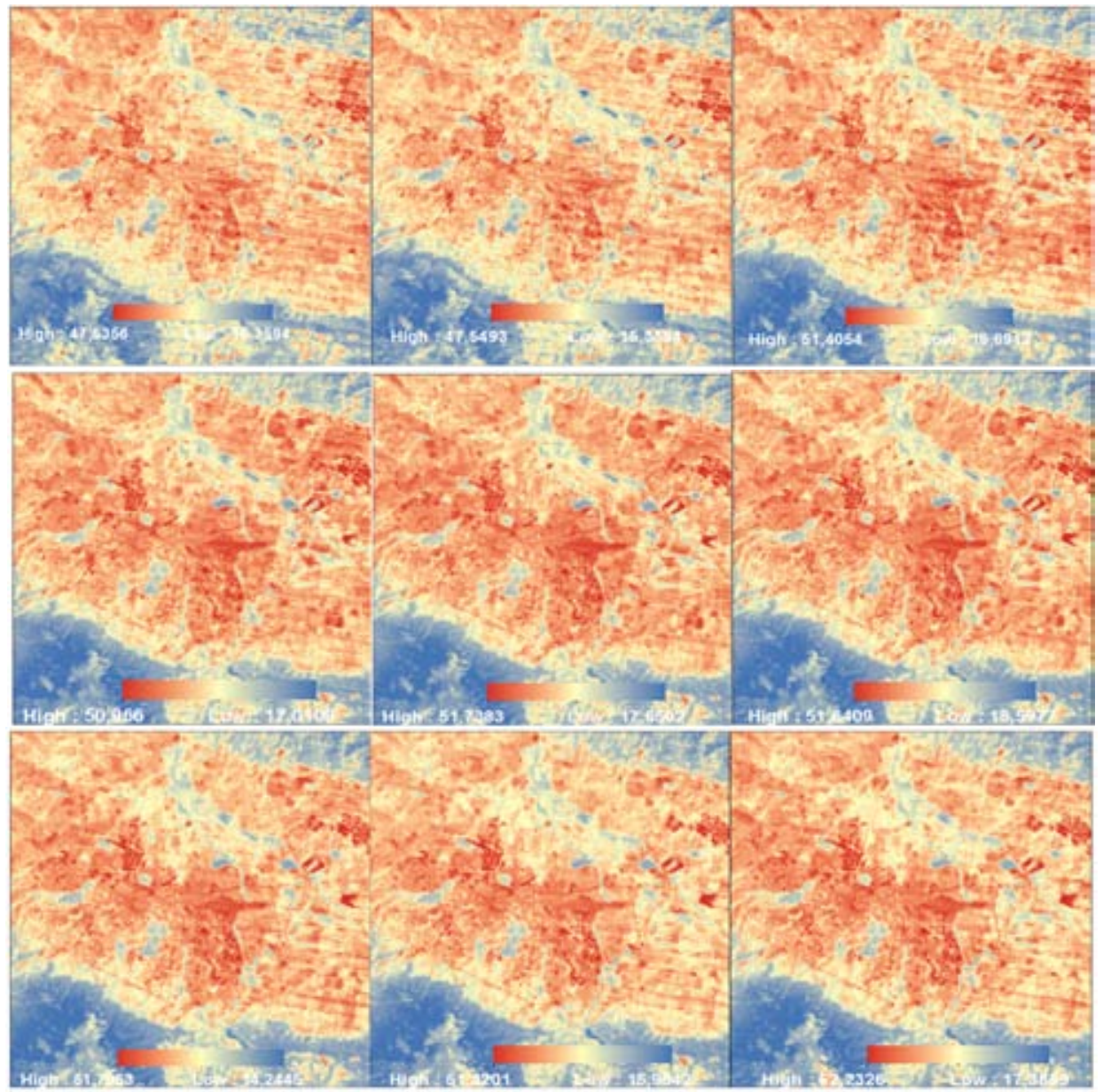

Fig. 3. LST averages for 9 five-year intervals, respectively 2001-2007, 2002-2008, 2005-2009, 2006-2010, 2007-2011, 2008-2012, 2009-2013, 2010-2014, and 2011-2015 (sequentially from left to right). 
In both methods, the same rating for surface temperature visualization is used. A Natural Breaks classification of seven classes has been used. The second method clearly shows an increase in pixel values. The UHI is apparently distinct on the first image where distinctive areas of extremely high temperatures are distinguished. In addition to the city, the increase in pixel values is also observed in the sub-urban areas - the Sofia valley resembles the urban area of the first image and in the surrounding mountains the bare mountain ridges are outlined.
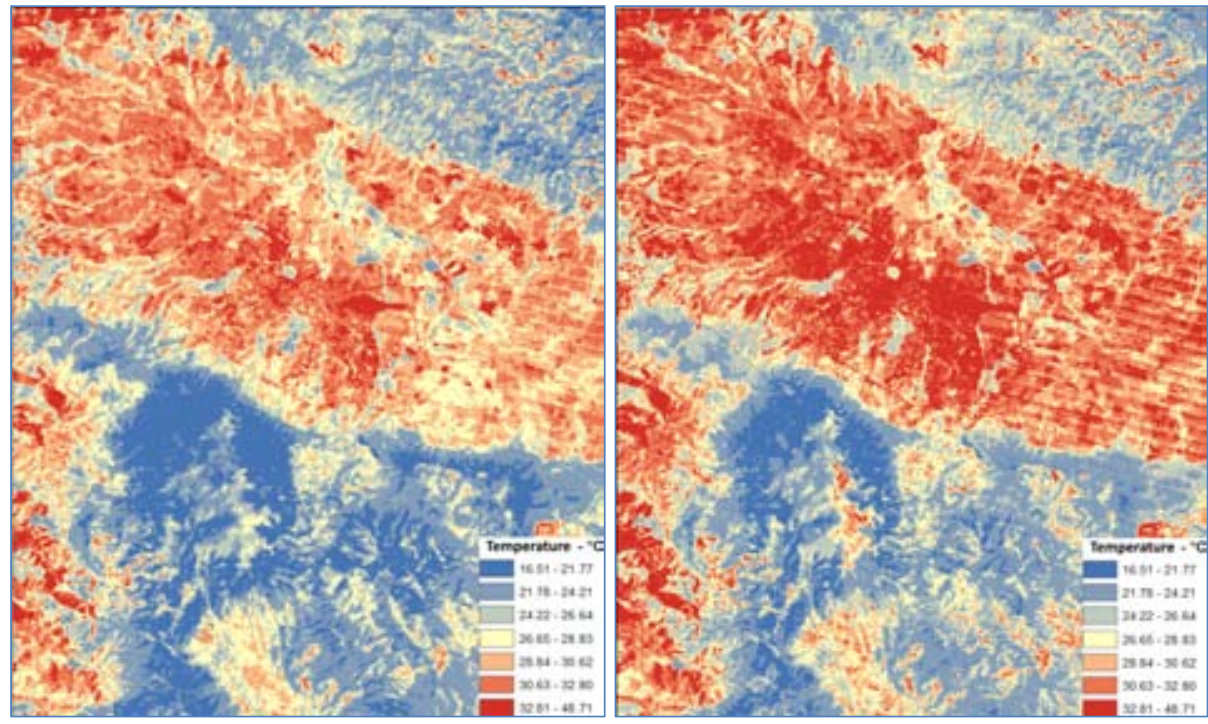

Fig. 4. LST averages for 2011-2015 by "Method 1" (left) and "Method 2" (right)

\section{Spatial model of the urban land surface temperature}

The city of Sofia forms a thermal island with typical spatial characteristics. Because of the terrain of the plain in the Sofia valley, a clear cliff or steep temperature gradient at the border with the town is observed only from the South, where the city territory borders directly with the Vitosha Mountain. From North, West and East there is a slight decrease in the temperature of the border between the town and the Sofia valley. The city is characterized by great heterogeneity of the temperature profile. The so-called "plateau", or the territory of a gradual increase in temperature from the periphery to the center of the city, is often interrupted by micro-urban thermal islands in places with large anthropogenic sites and industrial areas and so-called "heat sinks" or especially cold areas formed by large urban parks and places with distinct dense vegetation. The thermal profile is distinguished by a clear peak of the temperature in the city center. 
When it comes to the results obtained, it is interesting to look at the difference in the temperature profile depending on the spatial direction. By building a Nothwest-Southeast profile (Fig. 5a), the temperature profile is closer to the theoretical profile of an UHI. Surface temperature outside the city ranges from $30 \div 32{ }^{\circ} \mathrm{C}$. At the city border, micro-UHIs are caused by industrial objects rising to $36 \div 38{ }^{\circ} \mathrm{C}$, after which the temperature in the city moves about a degree over that outside the city in the range of $31 \div 33{ }^{\circ} \mathrm{C}$ until reaching the first cold zone due to the West Park. The temperature here decreases to $25^{\circ} \mathrm{C}$, and then it is constantly rising to reach the central city area. The temperature reaches $37^{\circ} \mathrm{C}$. Near the peak of the temperature in the center lies another cold zone linked to the South Park. The temperature then re-runs in the range of $30 \div 34{ }^{\circ} \mathrm{C}$ with interruptions of microUHI exceeding $40{ }^{\circ} \mathrm{C}$. At the eastern boundary there is Vrana Park, which forms another cold area, after which the temperature in the extra-urban part gradually decreases from $30^{\circ} \mathrm{C}$ downwards.

The temperature profile with the Southwest-Northeast direction is also interesting. Visually, the higher temperature in the North of the city is visible vis-à-vis the South. This is due to the southern neighborhoods situated at the foot of the Vitosha Mountain. They are characterized by low density of construction, lack of large anthropogenic sites, and more vegetation. The temperature profile on Fig. 5b start from the mountain where the temperature is $\sim 20^{\circ} \mathrm{C}$ before it reaches a brightly defined cliff on the city's border where the temperature rises sharply to $28{ }^{\circ} \mathrm{C}$. Then there is a rapid temperature growth of up to $30^{\circ} \mathrm{C}$ through the built-up footsteps of Vitosha Mountain. After the Sofia ring road, the temperature gradually rises to more than $33{ }^{\circ} \mathrm{C}$ in the center of the city and over $34{ }^{\circ} \mathrm{C}$ in the industrial zone to the North before passing through a typical cold zone created by the park of the Central Sofia Cemetery where the temperature drops to $25^{\circ} \mathrm{C}$. Thereafter, the temperature profile follows a smooth stroke at a decrease of $33{ }^{\circ} \mathrm{C}$ to about $30^{\circ} \mathrm{C}$ at the border with the extra-urban section, and continues the gradual decrease outside the city to about $28^{\circ} \mathrm{C}$.

To investigate the temperature increase by moving away from the mountain, we divided the urban area into several zones. For this purpose, we used areas or zones, meaning the boundaries of the city districts and the obtained LST after averaging the values for the period 2011-2015. In the two southern-most zones are the districts situated between Vitosha mountain and Okolovrasten pat Str. In the "Intermediate zone" bordering part of the "South Zone - East" there are several neighborhoods where there is still significant involvement of undeveloped areas. The zone located in the "Middle zone" of the city covers the neighborhoods between Ovcha kupel quarter and Mladost quarter. In the next zone there are the neighborhoods on the Lyulin quarter - Druzhba district and north of them. In particular zones are the "Center" quarter and the bigger urban and cemetery parks. For each zone, we calculated the average temperature. The following Fig. 7 show the temperature rise in the city from the South to the North by $>4{ }^{\circ} \mathrm{C}$. 


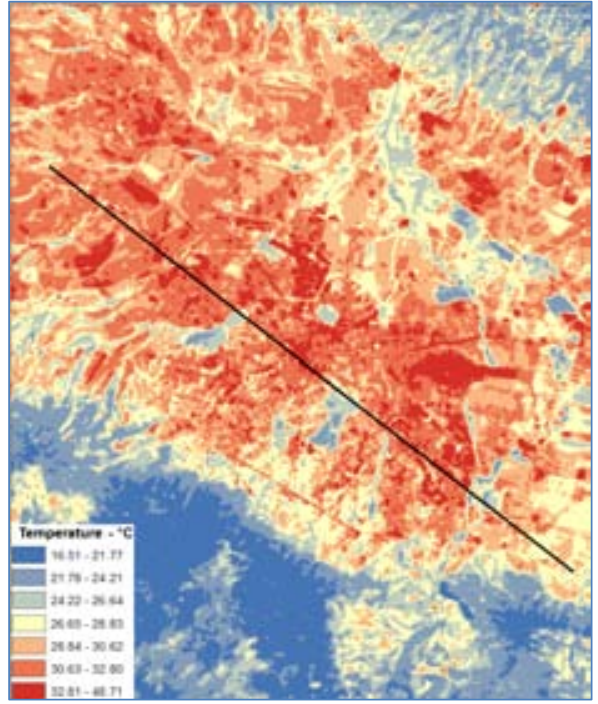

A

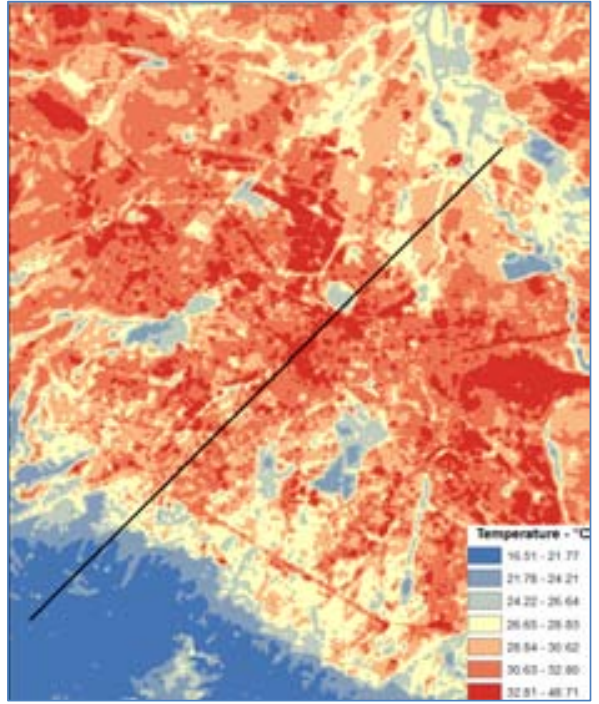

B

Fig. 5. (A) Temperature profile in Northwest-Southeast direction and (B) temperature profile in Southwest-Northeast on selected Landsat images ("Method 2") for 2011-2015.
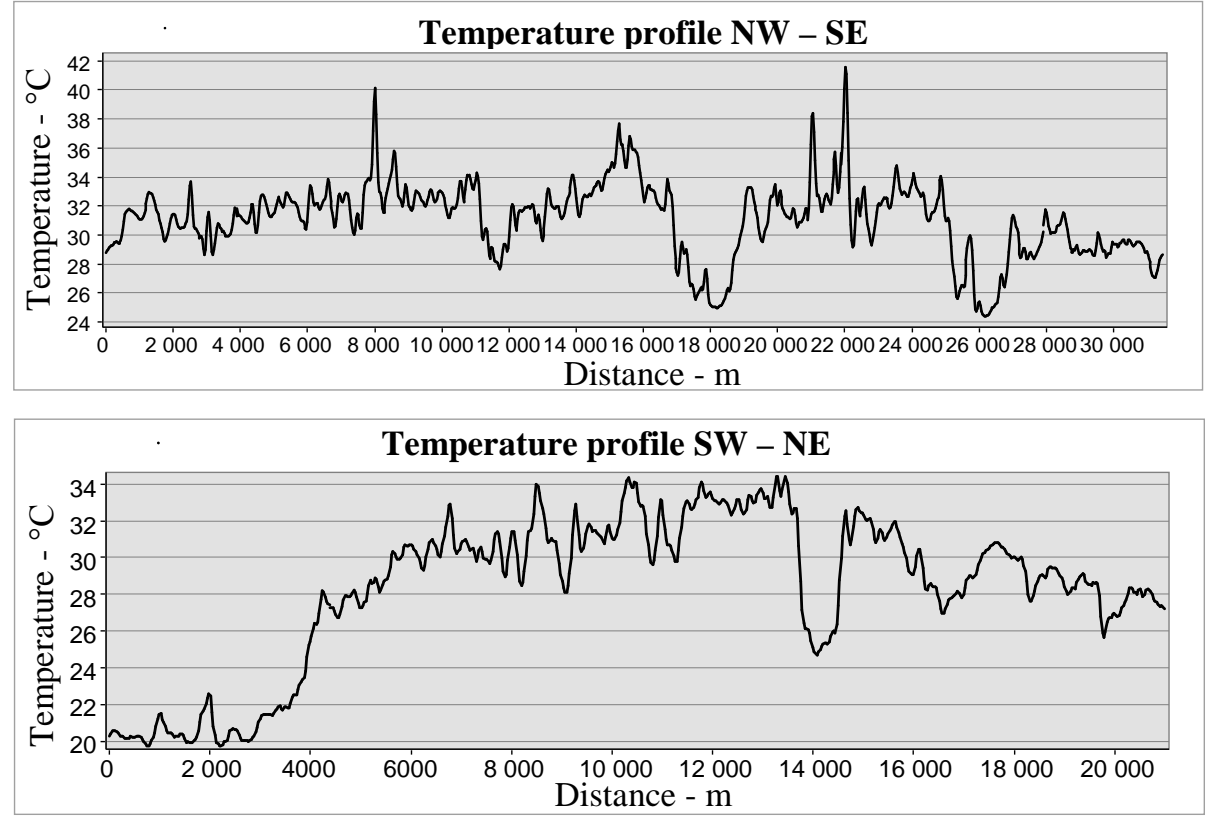

Fig. 6. Profile of the LST for Northwest-Southeast direction on selected Landsat images ("Method 2") for the period 2011-2015 (above). Southwest-Northeast LST on selected Landsat images ("Method 2") for the period 2011-2015 (below). 


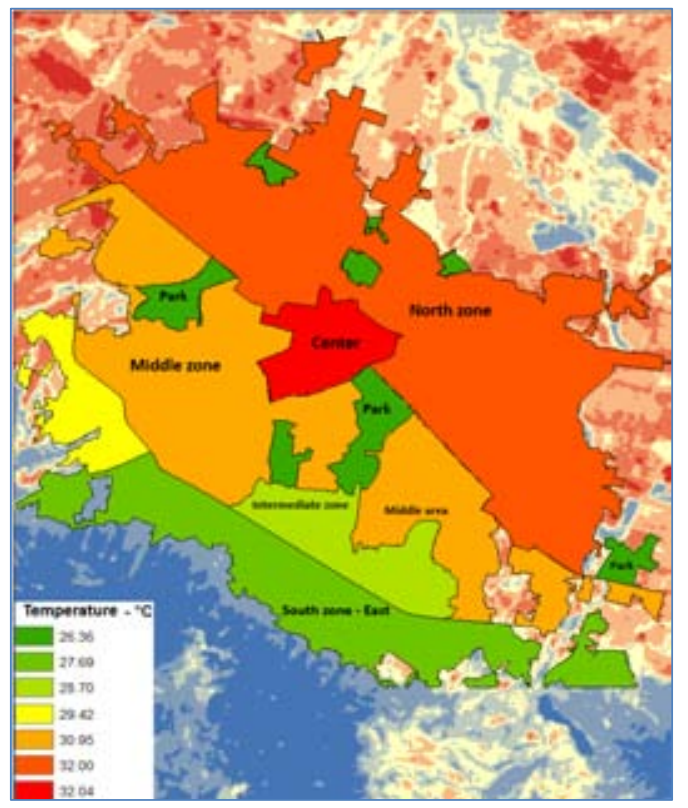

Fig. 7. Zoning of LST from South to North for selected Landsat images 2011-2015

\section{Land surface temperature by land cover type}

A number of factors previously commented influence the model of surface temperature in the urban environment and the formation of UHI. However, the most significant influence is the land cover. In order to assess the surface temperature in this aspect, we performed a visual classification of the studied area according to the type of the surface, the height and the density of the buildings, and the presence of vegetation. Thus, a total of 16 types of land cover are allocated, see Fig. 8: "Center" characterised by massive construction characteristic of the city center, dense built-in, adjacent buildings forming continuity along the streets; "Dense built-up urban area" - mostly high-rise building with a small distance between buildings"; "City cetre" with tall buildings with great free space between them; "Dense sub-urburban" with densely built areas with predominantly low-rise and a "Low-rise" subdivision including industrial sites and greater distance from the previous class; "Industrial area" with mainly industrial sites and almost no vegetation; "Village" of a low built-up area with a significant presence of vegetation and gardens; "Park" with dense vegetation mixed with anthropogenic objects; "Village zone" similar to the class of a densely built suburb but outside the urban territory; "Barren land" are areas without construction and high vegetation, mainly tilled arable land; "Forest" with high forest species without free spaces; "Sparse vegetation" is high vegetation with free spaces; "Perennials" are plantations with perennial crops; "Water bodies", "Airport"; and "Streets". 


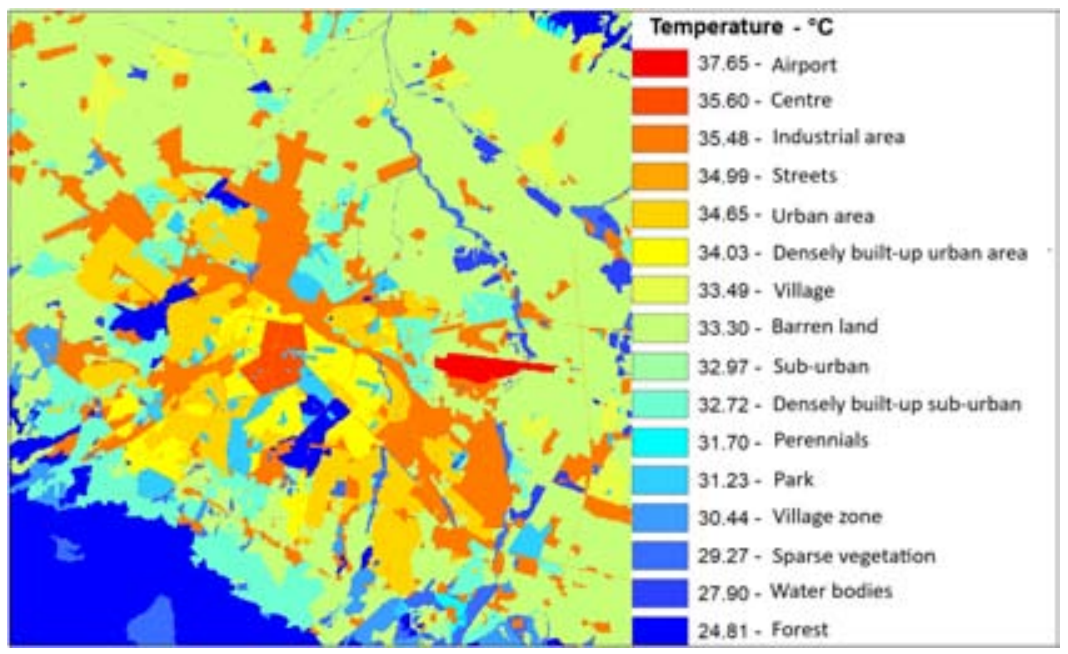

Fig. 8. LST based on visual classification on selected images for 2010-2012

Since the orthophoto images from 2011 were used for the visual land cover classification, images from the same year should be used for the analysis. Due to problems with Landsat 7 SLC, we can not only use a single 2011 image. For the purpose of better representation and consistency of the analysis, we used images from the previous and next year. This gives an LST image with averaged values for 2010, 2011, and 2012. The visual image classification and the resulting image were used to obtain the average temperature value for each class. From the above image, it can be seen that the city center is not the hottest point. This role is occupied by Sofia Airport, which can be considered as a separate site, as only the runways and the empty spaces between them are included in this class. This combination of predominantly impervious horizontal surfaces spaced from vertical objects forming shadows and voids, which also are significantly heated under dry conditions and prolonged exposure to direct sunlight, results in the formation of the highest temperature above $37.5^{\circ} \mathrm{C}$ in the thus performed classification. In this line of thought, streets should demonstrate the same high values as they also form a class of impervious surfaces. Here, however, the temperature values are influenced by the high vegetation along some streets that lowers the temperature both through the shadows formed and by hiding them from the field of view of the Landsat sensor. Besides vegetation and neighboring buildings, they form shadows on the streets, which further reduce the temperature. The set of factors results in an average of $34.99^{\circ} \mathrm{C}$ for class "Streets". The "Center" class shows a marked peak in the central city area. Here the vegetation is limited by the extremely dense and high-rise construction, which is almost continuous along the streets. Very close in temperature value is the "Industrial area" class. Both classes reported a value of 
about $35.5{ }^{\circ} \mathrm{C}$. However, some industrial zones or individual industrial sites may significantly exceed these values on Fig. 9 is shown a rooftop of large industrial object heated to $>50^{\circ} \mathrm{C}$.

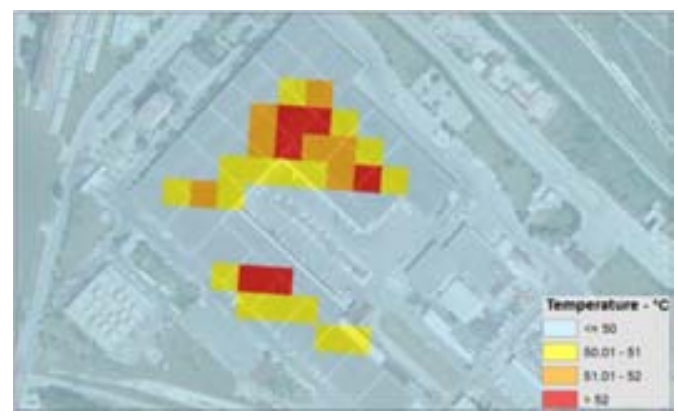

Fig. 9. A micro-UHI formed by a large industrial site which temperature exceeds $50{ }^{\circ} \mathrm{C}$

Particularly interesting are the classes "Urban area" and "Densely built-up urban area". Despite the denser construction in the second class a lower temperature of about $0.6^{\circ} \mathrm{C}$ is reported. It combines high and low-rise buildings, as well as the presence of more vegetation, which is typical for low-rise sites. Characteristic of the first class are the high-rise residential buildings with a greater distance occupied by empty spaces. The rise in temperature is due, on the one hand, to the large facades directly exposed to sunlight, and on the other to the characteristic very high heating of the empty areas, under certain conditions approaching impervious surfaces. The difference in temperature between the two described types of surface is even greater if we take into account only individual zones that are closest to the description of the class. A very characteristic area approximating to the description for class "Urban area" is Lyulin district. The same applies to the Reduta and Geo Milev districts as far as the "Dense built-up urban area" class is concerned. Only those areas are represented in Fig. 10, the data and methods of analysis used to be identical to the above.
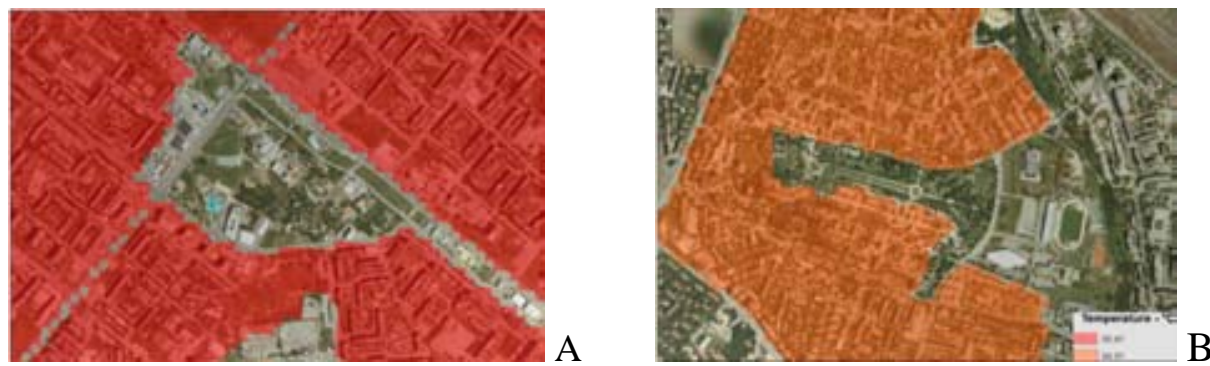

Fig. 10. A comparison between characteristic areas for "Urban area" (A) and "Densely built-up urban area" (B) 
The "Village" and "Densely built sub-urbran" classes fall into one category with the difference that the first falls within urban territory. The reason the class "Village" to have a higher temperature of near $0.8^{\circ} \mathrm{C}$ probably lies in the southern neighborhoods of the town located at the foot of the Vitosha Mountain. These areas are densely built with low-rise buildings, but also have a significant presence of high vegetation. Considering that these areas occupy a significant part of the whole class can be explained the relatively large difference in temperature ratio. Similar is the reason why the "Sub-urban" class, which is characterized by more dilute, often industrial buildings and bare areas, has a near $0.3{ }^{\circ} \mathrm{C}$ higher temperature compared to the "Dense sub-urban" class.

More specific is the "Barren land" class. It has been attributed to arable and uncultivated areas without anthropogenic sites and without high vegetation. Here are the most common fields occupied by grasses or areas sown with low crops. The bare terrain is characterized by high temperatures, especially during the summer months, with prolonged droughts and hot days. This is the reason sometimes such areas are difficult to distinguish from impervious surfaces. In addition, lower vegetation loses its water content more quickly, which is another factor for the high average temperature of the class of $33.3^{\circ} \mathrm{C}$. The following Fig. 11 demonstrate the heating of a barren land to about $38^{\circ} \mathrm{C}$.

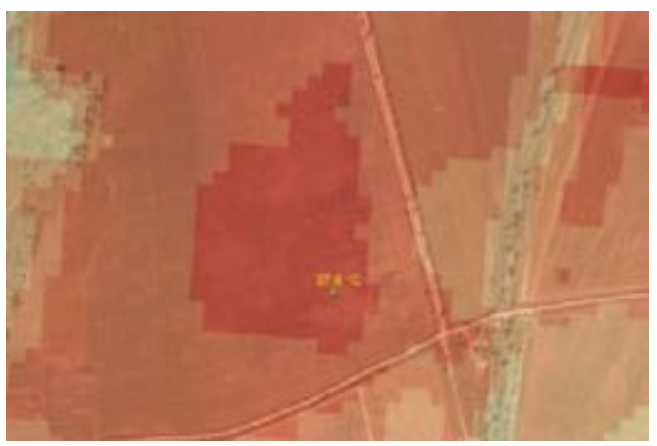

Fig. 11. "Barren land" class surface temperature

The "Park" class is a territory occupied by high vegetation and anthropogenic sites such as alleys, low buildings, and other waterproof objects. For example, large parts of the Borisova Garden and West Park parks fall into the "Forest" class. Therefore, the "Park" class forms a temperature of $31.23{ }^{\circ} \mathrm{C}$, which is $0.8^{\circ} \mathrm{C}$ above the temperature of the "Village zone" class, which is characterized by sparsely built areas with low-height buildings and rich vegetation. For comparison, the "Forest" class records the lowest temperature in the classification $24.81{ }^{\circ} \mathrm{C}$, which is close to $6.5^{\circ} \mathrm{C}$ lower than the "Park" class. It is actually interesting to note that "Water bodies" have a higher temperature to "Forest" class. 
The "Water bodies" class shows $27.9{ }^{\circ} \mathrm{C}$, which is $>3{ }^{\circ} \mathrm{C}$ above the "Forest" class, see Fig. 12. This is due to several reasons. In the classification, there are small objects such as urban pools and water bodies in parks that fail to compensate for the impact of the pixel portion of the image falling outside the water. In fact, this is also one of the possible applications of the thermal images. They can detect water bodies that are not highlighted at the time of acqusition, and can hardly be distinguished by an RGB image composite.

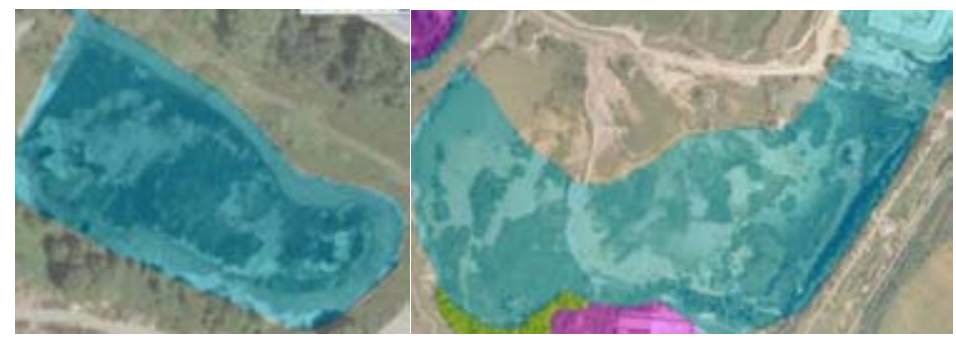

Fig. 12. "Water bodies" class surface temperature

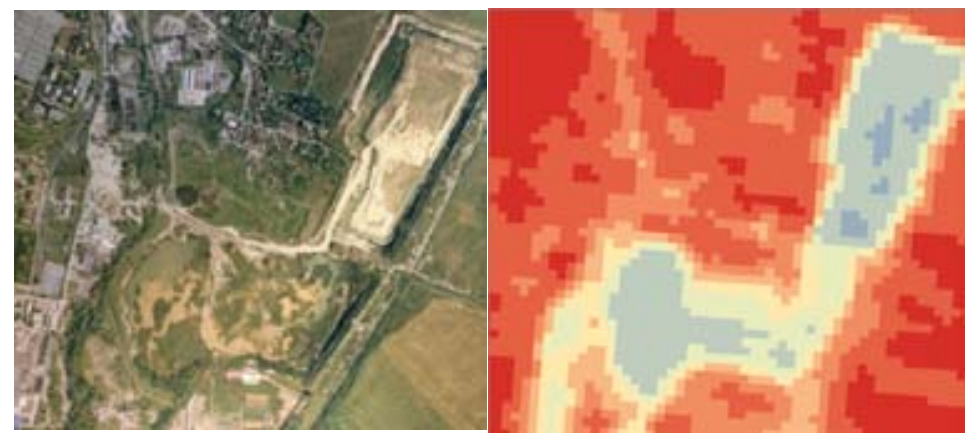

Fig. 13. Display of a dry water object (left) on a thermal image (right)

The following Fig. 14 show the course of temperatures by classes. The red line represents an average value of selected images with the most similar acqusition conditions for the 2010-2012 period. The blue line contains averages for the same period but for all available images in the database. These two lines represent the same period, and it is seen that as the maximum temperatures increase, the impact of waterproof areas is increased. It is interesting to compare the 2010-2012 and the last five-year (2011-2016) averages, with all the available images taking part. The graph shows a definite increase in temperature, especially in classes with predominantly impervious areas. Earlier we mentioned that as the maximum temperatures increase, the impact of impermeable surfaces increases. To support this statement, a graph drawn from the temperature difference between the two 
groups of images for the period 2010-2012 is shown in Fig. 14. The gradual reduction of the difference between the classes with mostly impermeable surfaces to the classes with increased vegetation influence is seen.
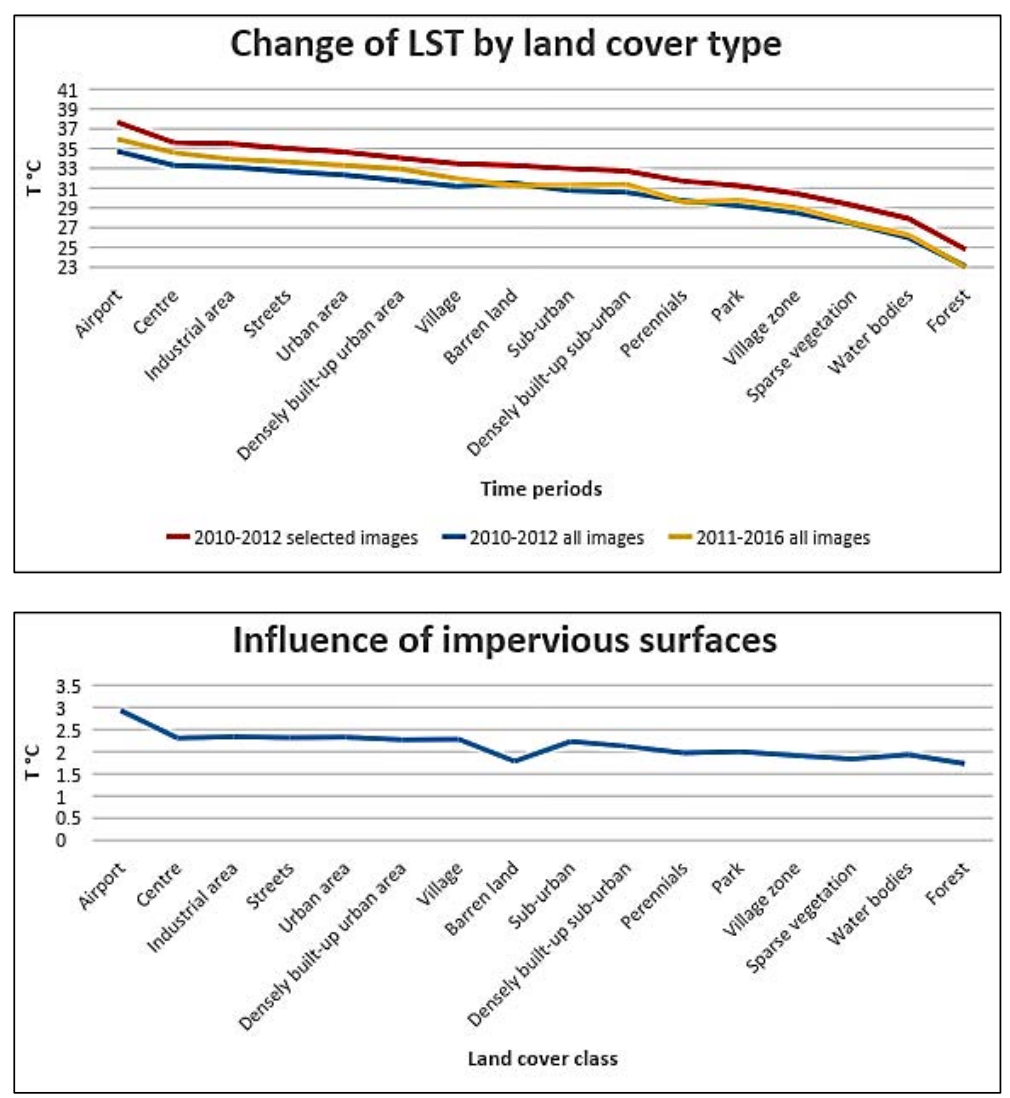

Fig. 14. Change of surface temperature by type of land cover (top). Influence of impervious surfaces on the surface temperature (bottom).

\section{Estimation of the land cover change according to LST}

As it has already become clear, waterproof (anthropogenic) surfaces are heated significantly more than the permeable (natural) surface. Considering the difference in heating of different surfaces, thermal imaging can be used to detect changes in the earth's surface. The Fig. 15 show the difference in temperature between images from 2001 to 2015. Blue zones mean that the temperature has fallen, and red zones suggest an increase in value. 


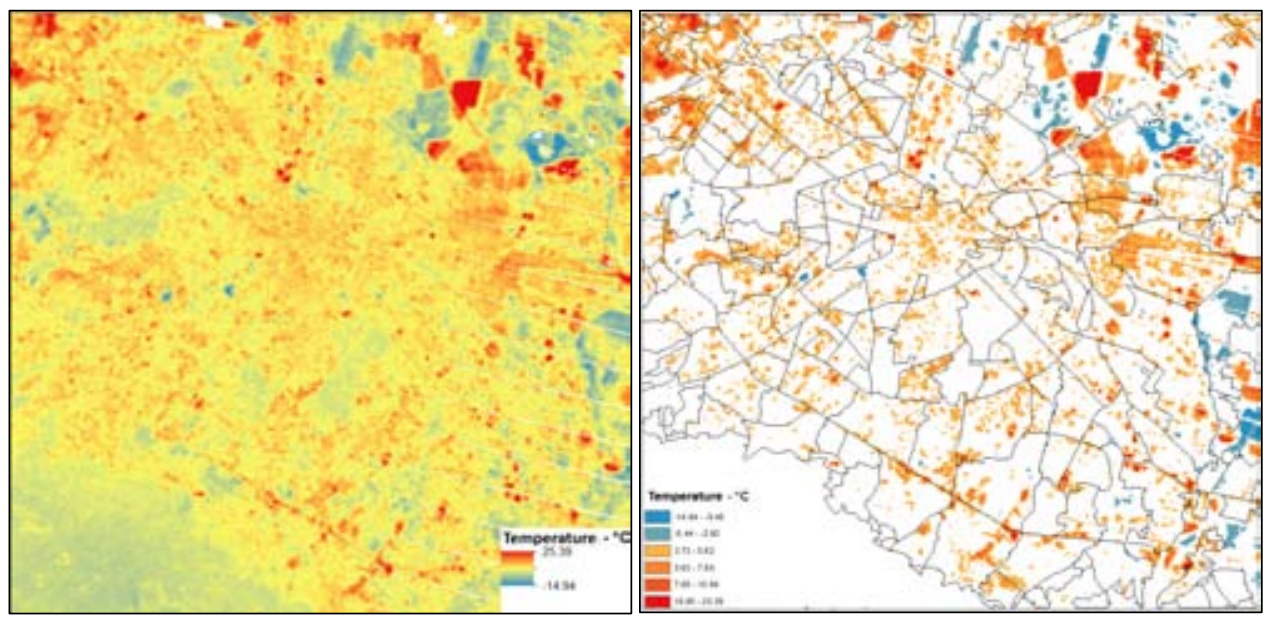

Fig. 15. Difference in the LST between 2001 and 2015 images (left), zones with significant difference in LST in 2001 and 2015 images (right)

The left image on Fig. 15 show warming in the city center and other parts of the city. In addition, there are some strong areas where objects are built or removed. The development of the so-called "Southern Ring Road".

Along this part of the ring road there are numerous industrial or office buildings that raise the temperature. The resulting image is further classified to remove the areas with a minimum difference in the values depicting the most significant changes. On the right image on Fig. 15 are clearly seen the areas with more significant changes. This result confirms the warming in the city center. In addition, larger areas with higher values are observed in the North in Orlandovtsi, in the West in the Lyulin, Fakulteta, Ovcha Kupel, Southeast along the Ring Road and Simeonovo, Hladilnika quarter between South Park and Loven Park, Sofia Airport and the Levski quarter. Areas with reduced temperatures are significantly less. Within the city, there are two such areas close to the city center, which are a result of the removal of large industrial sites. There are many zones with low temperatures in the East and North-East direction. However, only one of them is a consequence of a change in the land cover, namely the formation of a new water body. The rest are mostly arable land where it is important whether the land is plowed or sown. The red fields in the northeastern and northwestern suburbs are also due to the fields, as the bare earth surface is significantly more heated.

We will look at some of the more characteristic changes. Fig. 16 show some instances of development of new city parks, emergence of large industrial sites, removal of industrial sites, and appearance of new water bodies. Changes in the land cover were found by the above analysis of the surface temperature difference in 2001 and 2015. 

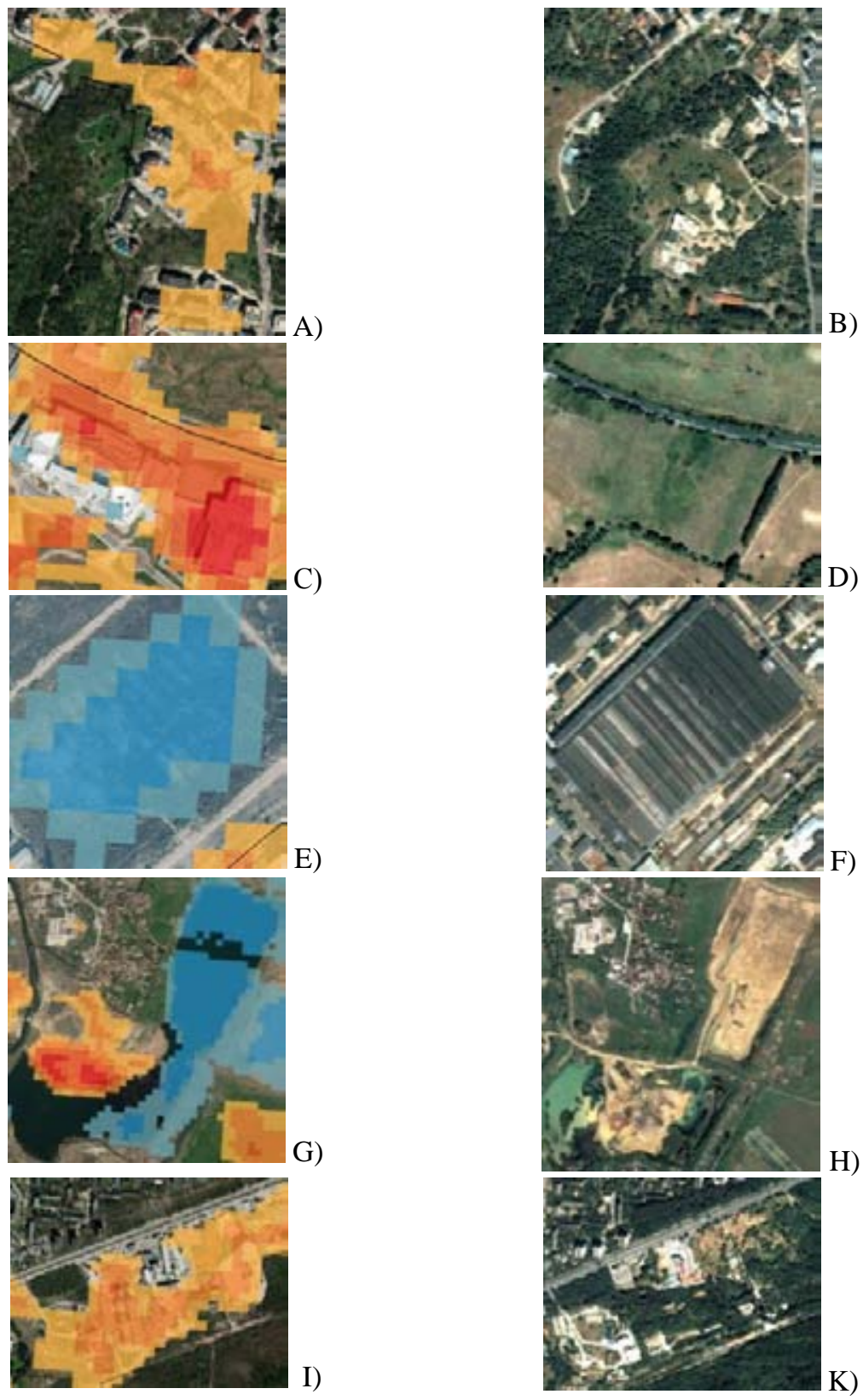

Fig. 16. Part of South Park: 2015 (A) and 2001 (B); construction of industrial sites along the Ring Road: 2015 (C) and 2001 (D); removal of industrial sites in "Krasna Polyana 3": 2015 (E) and 2001 (F); formation of a new water body and correction of an old one: 2015 (G) and 2001 (H); part of the Hunting Park: 2015 (I), and 2001 (K) 
Despite the possibility of detecting changes in the land cover, an automatic classification and assessment of the changes would be quite difficult to implement. The reasons lie in the low SR of the termal bands for such purposes, the specific emission of the different materials, and the acquisition conditions. In our case, daytime imagery is selected from the hottest and driest period of the year. Under such conditions, the terrain is heated almost like an impermeable surface, making it even more difficult to remove the impermeable areas, see Fig. 17.

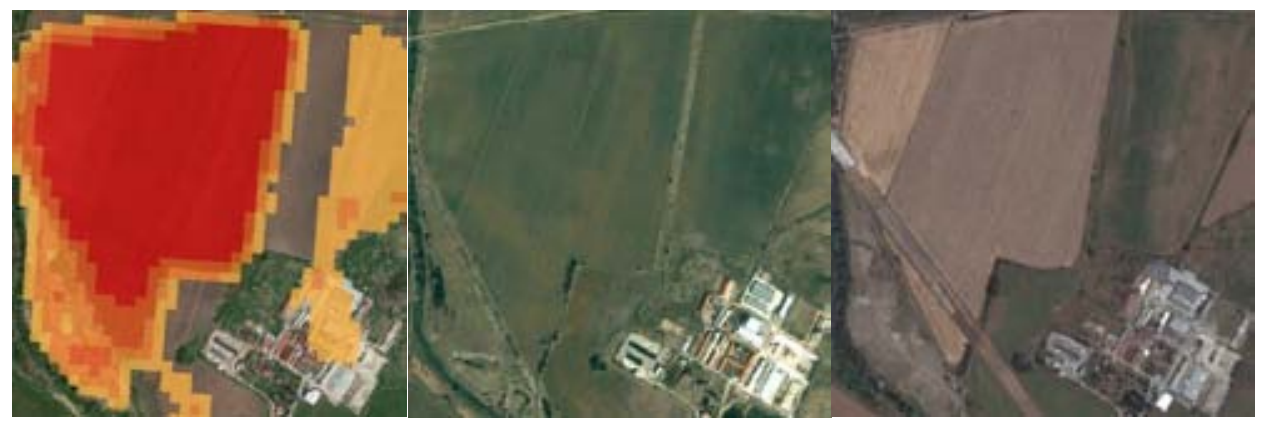

Fig. 17. The difference in the arable LST between the two images is $16.6^{\circ} \mathrm{C}$ (left). In the middle, the levels are close to the time of shooting in 2001 and to the right in 2015.

Since the factors influencing the temperature trend are too much there is no way to assign a specific value or range of temperature to a given type of land cover. At present, it is difficult to automatically classify the earth's surface automatically with thermal imaging, and from there to analyze the changes. However, the trend of surface temperature can be judged for the development and alteration of the surface as a whole.

\section{Estimation of the LST dynamics for the investigated time period}

As from the initial visual analysis of the processed images, we have seen that there is a tendency towards increasing saturation of the pixel values. If we compare two images of different years, the analysis will not be correct, as the temperature is quite variable. Therefore, working on average data, we have reason to make general conclusions about changes in the urban environment.

All images averaged with "Method 2" are used in Fig. 18. For each class of the earlier visual classification, we took the temperature values by a period. Over time, a gradual rise in temperature is evident, possibly due to the increase in waterproof surfaces at the expense of green areas. To confirm the rise in temperature values we will also use the boundaries of the earlier zoning from the South to the North. The bottom image on Fig. 18 confirm the temperature increase in all zones. 

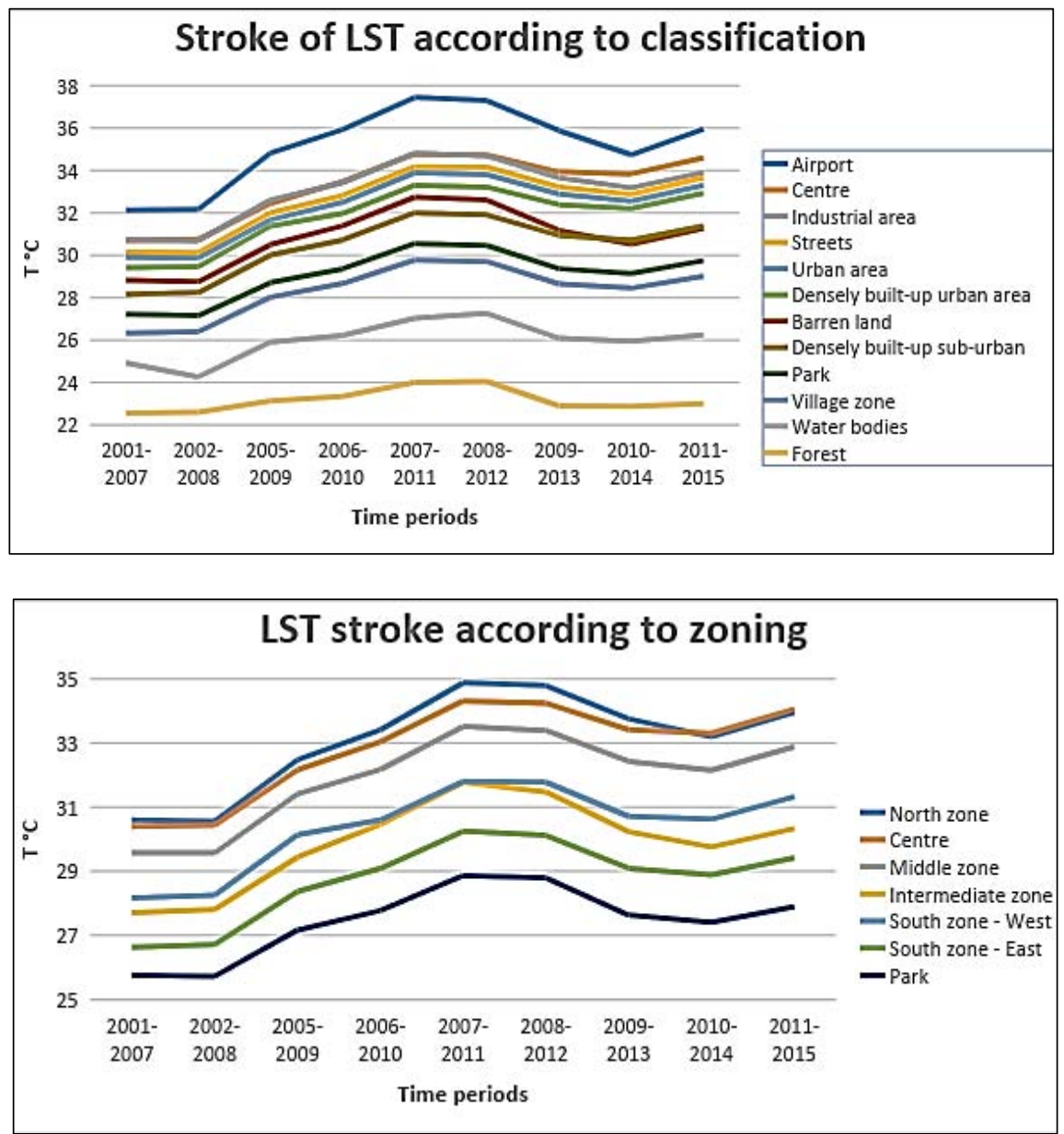

Fig. 18. LST course for different land cover classes by period (selected images, "Method 2") (top) and LST course for different zones by period (selected images, "Method 2") (bottom)

However, the absolute temperature difference between the first and the last period is different. From the figure, it appears that areas with less vegetation have increased the temperature more than those with more vegetation. The temperature in the central city area increases by $>3.5^{\circ} \mathrm{C}$ for the whole period, the Northern and the Middle zone by $\sim 3.3{ }^{\circ} \mathrm{C}$, while in the Intermediate zone and the South Zone East the value increases by about $2.7^{\circ} \mathrm{C}$. Parks show the lowest increase of $2.1^{\circ} \mathrm{C}$. 


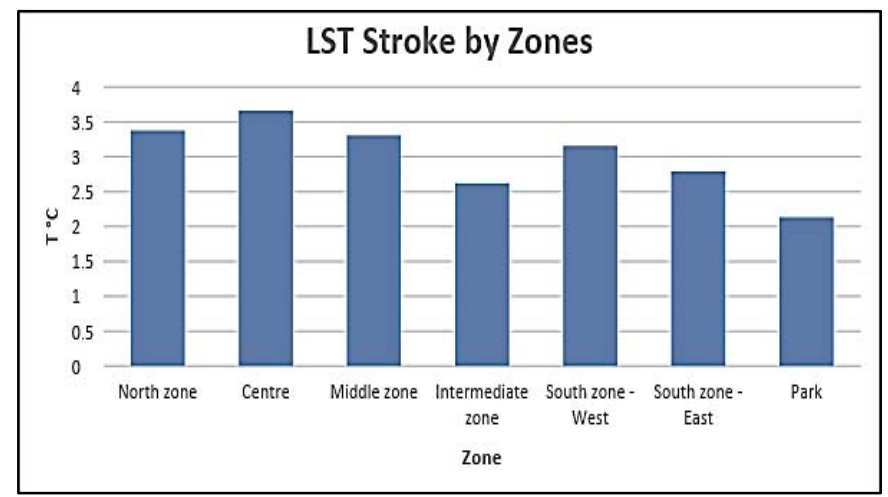

Fig. 19. LST Stroke in the Sofia city zones

However, we can not but notice the extremely similar temperature increase for all areas, despite the differences in the land cover. The same is true of the upper graph showing the course of temperature according to the earth cover class. By analyzing the temperature dynamics between all zones, we find that the correlation between the zones is too high. The lowest coefficient between two zones is 0.972.

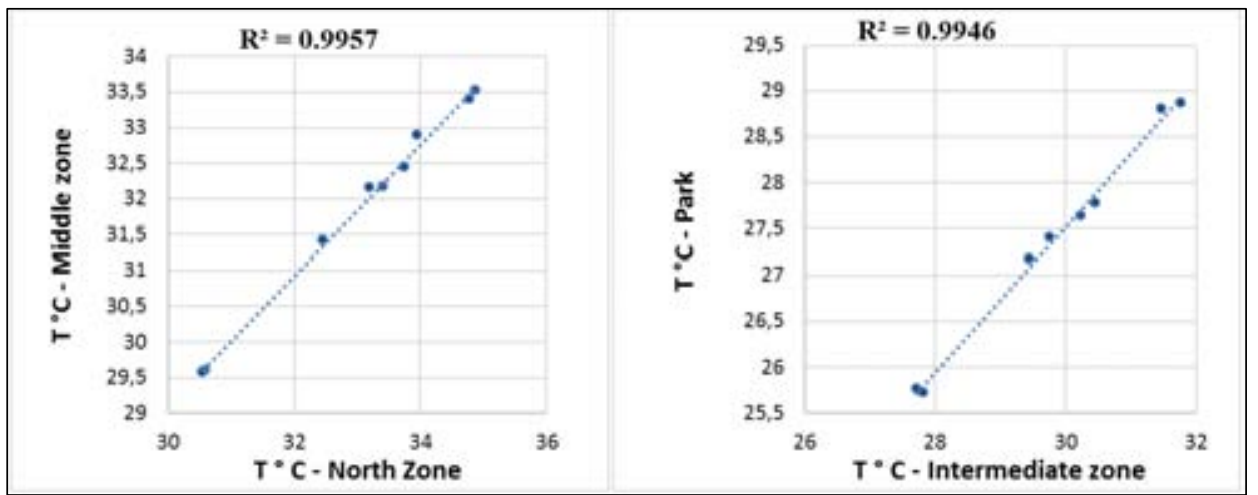

Fig. 20. Correlation between North Zone and Middle Zone (Left) and Park and Intermediate Zone (right)

From recent analyzes, we can assume that the increase in the temperature of the land cover on the data presented does not is due only to the change of the land cover and the increase of the impermeable surfaces at the expense of the vegetation. That is why we analyzed the air temperature trend as well. For the date of acquisition of each image taken in the above analyzes, we took the air temperature to $12 \mathrm{~h}$ according to the data provided by NIMH-BAS. For comparison Landsat images were taken around 12:00 h local time. For 2015 only, we took the 
value from the wunderground.com website. The following graph, see Fig. 21, shows a comparison of the air temperature and LST dynamics with "Middle Zone" and on Fig. 21 (bottom) shows the intensity of the UHI in Sofia.
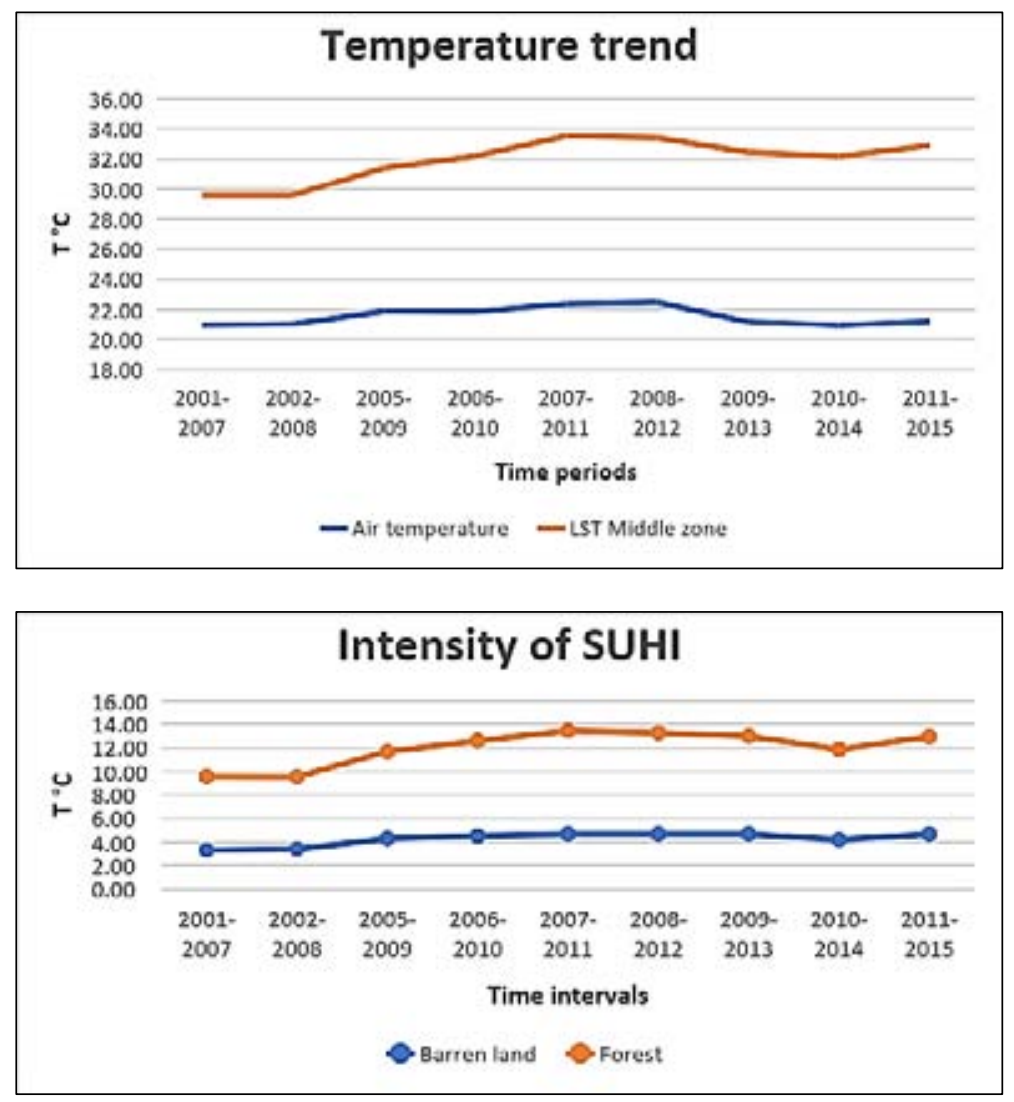

Fig. 21. Comparison of the air temperature at 12:00 h according to NIMH-BAS data and the surface temperature at about 12:00 $\mathrm{h}$ according to Landsat data (top). It is seen that the two lines follow a similar trend, as evidenced by the regression analysis. Intensity of the city UHI based on "Barren land" and "Forest" (bottom)

At first glance, the correlation dependence is not satisfactory, Fig. 22. If we analyze the situation more closely, we will see that, if we exclude the three points below the trend line, then the rest form a linear dependence. These separated points themselves appear to lie on one line. These are actually the last three groups. 


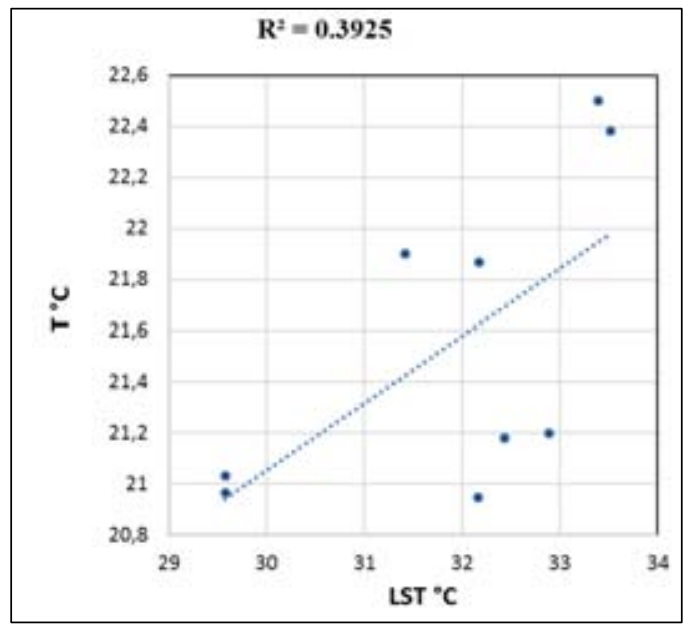

Fig. 22. Correlation between air temperature and land surface temperature

To try to estimate the temperature rise due to the human factor, we also analyze the intensity or magnitude of the the urban heat island. As we quoted earlier, this represents the difference between the warmest zone in the city and the base sub-urban temperature. In the case of base sub-urban temperature we will use two types of surface from the visual classification - "Barren land" and "Forest". As the warmest area of the previous analyzes, Sofia airport was outlined.

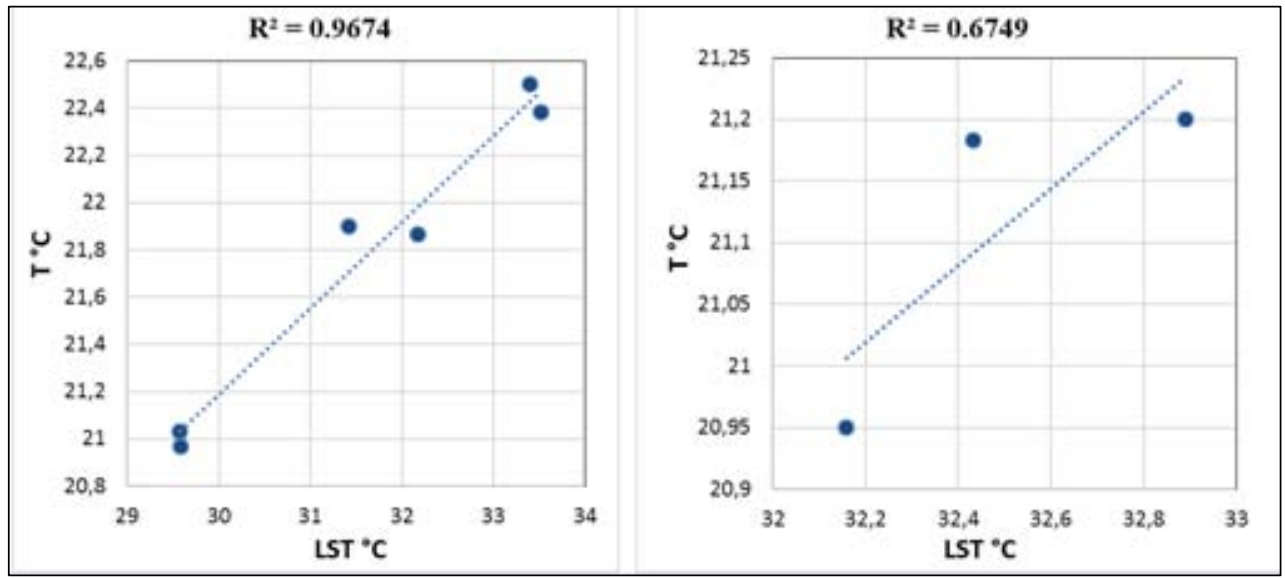

Fig. 23. Correlation between air temperature and LST: the first 6 periods (left) and the last three periods (right)

In average, the intensity of the UHI is around $8{ }^{\circ} \mathrm{C}$. To complete the analysis we will estimate the percentage increase in temperature values using the 
highest correlation periods. We will take the first two out of them, as they look rather anomalous in comparison with the others. In total, four periods are from 2005-2009 to 2008-2012. For this seven-year interval, the air temperature in the latter group is $2.74 \%$ higher than the first group. By the same method, the thermal island intensity is higher at the end of the period by $8.79 \%$ calculated on the "Barren land" class, $13.41 \%$ calculated on the "Forest" class or $12.16 \%$ higher on average.

Table 2. Air T ${ }^{\circ}$ and LST in the "Middle Zone"

\begin{tabular}{|c|c|c|}
\hline Time Period & Air temperature $-\mathbf{T}^{\circ} \mathbf{C}$ & LST Middle zone \\
\hline $2001-2007$ & 20.97 & 29.58 \\
\hline $2002-2008$ & 21.03 & 29.57 \\
\hline $2005-2009$ & 21.90 & 31.42 \\
\hline $2006-2010$ & 21.87 & 32.17 \\
\hline $2007-2011$ & 22.38 & 33.52 \\
\hline $2008-2012$ & 22.50 & 33.40 \\
\hline $2009-2013$ & 21.18 & 32.43 \\
\hline $2010-2014$ & 20.95 & 32.16 \\
\hline $2011-2015$ & 21.20 & 32.89 \\
\hline
\end{tabular}

Table 3. Intensity of the city UHI based on "Barren land" and "Forest" classes

\begin{tabular}{|c|c|c|c|}
\hline \multirow{2}{*}{ Period } & \multicolumn{3}{|c|}{ Intensity of UHI $-\mathbf{T}^{\circ} \mathbf{C}$} \\
\cline { 2 - 4 } & Barren land & Forest & Average \\
\hline $2001-2007$ & 3.31 & 9.58 & 6.44 \\
\hline $2002-2008$ & 3.41 & 9.56 & 6.48 \\
\hline $2005-2009$ & 4.31 & 11.68 & 8.00 \\
\hline $2006-2010$ & 4.54 & 12.57 & 8.56 \\
\hline $2007-2011$ & 4.70 & 13.43 & 9.07 \\
\hline $2008-2012$ & 4.69 & 13.25 & 8.97 \\
\hline $2009-2013$ & 4.71 & 12.97 & 8.84 \\
\hline $2010-2014$ & 4.22 & 11.86 & 8.04 \\
\hline $2011-2015$ & 4.68 & 12.94 & 8.81 \\
\hline
\end{tabular}

If we subtract the microclimatic influence of the air temperature from the average we will get a $9.42 \%$ increase in the urban surface temperature in the urban area for the period 2005-2012. This should be the rise in temperature due to the withdrawal of parts of construction parks, the emergence of new areas with built- 
up blocks of flats, the emergence of new large industrial sites, the collapse of the housing stock, the replacement of old low-rise buildings with new larger buildings are likely to be affected by many other anthropogenic factors accompanying the undeniable growth of the city, such as the increase in road traffic, for example. At the same time, in the analysis of the changes in the land cover in the town we have found an insignificant number of areas with a decrease in temperature, which further supports the fact that the dynamics of the city's temperature is in the direction of constant increase.

\section{Conclusion}

Conclusion for the analysis of the processed images we can categorically confirm the formation of a city urban heat island on the surface of the studied territory. This fact is supported by both a visual evaluation and a subsequent indepth analysis of the results. Two methods of averaging images are used. In "Method 1," we have three equal intervals, which include all the available images in the database evaluated as valid for inclusion in the analysis, while in "Method 2" we have 9 intervals based on selected images (one per year) with similar acquisition conditions.

The model of the UHI shows a marked increase in temperatures from South to North. The temperature profile shows a different manifestation in the West-East direction to the South-North direction. In general, the thermal island is characterized by heterogeneity, as well as the typical UHI cliffs, plateaus, microUHI and "cold" islands.

The influence of the type of land cover has been analyzed. For this purpose, a visual classification has been drawn up, whereby the surveyed territory is divided into 16 classes. Undoubtedly the influence of the so-called "Impervious surfaces" is on the rise in city temperature. A detailed analysis of the data over the entire survey period shows a gradual rise in the city's temperature due to the change in the urban environment. In average, the intensity of the UHI of Sofia is around $8{ }^{\circ} \mathrm{C}$.

\section{References}

1. Rao, P.K. Remote sensing of urban "heat islands" from an environmental satellite. Bulletin of the American meteorological society, 1972, 53, 7, 647-48.

2. Gallo, K.P. et al. The Use of NOAA AVHRR Data for Assessment of the Urban Heat Island Effect, Journal of Applied Meteorology, 1993, 899-908. DOI: 10.1175/1520-0450(1993)032<0899:TUONAD>2.0.CO;2.

3. Carlson, T.N., J.A., Augustine, and F.E. Boland, Potential application of satellite temperature measurements in the analysis of land use over urban areas. Bulletin of the American Meteorological Society, 1977, 1301-03.

4. Matson, M., E.P., Mcclain, Jr, D.F., McGinnis and J.A. Pritchard, Satellite detection of urban heat islands. Monthly Weather Review, 1978, 106, 12, 1725-34. 
5. Price, J.C. Assessment of the urban heat island effect through the use of satellite data. Monthly Weather Review, 1979, 107, 11, 1554-57.

6. Kidder, S.Q., and H.T. Wu, A multispectral study of the St. Louis area under snowcovered conditions using NOAA-7 AVHRR data. Remote Sensing of Environment, 1987, 22, 2, 159-72.

7. Roth, M., T.R., Oke, and W.J. Emery, Satellite-derived urban heat islands from three coastal cities and the utilization of such data in urban climatology. International Journal of Remote Sensing, 1989, 10, 11, 1699-1720.

8. Carnahan, W.H., and R.C. Larson, An analysis of an urban heat sink. Remote sensing of Environment, 1990, 33, 1, 65-71.

9. Leak, S.M., and G. Venugopal, Thematic Mapper thermal infrared data in discriminating selected urban features. Int. J. Rem. Sens., 1990, 11, 5, 841-57.

10. Watanabe, H., H., Yoda, and T. Ojima, Urban environmental design of land use in Tokyo metropolitan area. Energy and Buildings, 1990, 15, 1-2, 133-37.

11. Gastelois, B.C., E.S., de Assis, M., Ar, \& I.L. Gastelois-UFMG, Environmental climatic conditions in Belo Horizonte: an urban heat island investigated by remoted sensing, 1991.

12. Saito, I., O., Ishihara, and Katayama, T. Study of the effect of green areas on the thermal environment in an urban area. Energy and Build., 1990, 15, 3-4, 493-98.

13. Quattrochi, D.A., and M.K. Ridd, Measurement and analysis of thermal energy responses from discrete urban surfaces using remote sensing data. International Journal of Remote Sensing, 1994, 15, 10, 1991-2022.

14. Aniello, C., K., Morgan, A., Busbey, and L. Newland, Mapping micro-urban heat islands using Landsat TM and a GIS. Comput. \& Geosci., 1995, 21, 8, 965-969.

15. EUROSTAT - City Statistics Illustrated, 2015. URL: http://ec.europa.eu/eurostat/cache/ RSI/\#?vis=city.statistics (21 December 2016).

16. Climate guide of People's Republic of Bulgaria. Vol. 3: Air temperature, soil temperature, frost. Sofia, Bulgaria, 1983. (in Bulgarian)

17. National Statistical Institute (NSI). Population by districts, municipalities, settlements and age to 01.02.2011. http://goo.gl/UXt2pf (22 December 2017).

18. Jimenez-Munoz, J.-C. and J.A. Sobrino, Split-Window Coefficients for Land Surface Temperature Retrieval From Low-Resolution Thermal Infrared Sensors, IEEE Geoscience and Remote Sensing Letters, 2008, 5, 4, 806-09. DOI: 10.1109/LGRS.2008.2001636. 


\title{
ОЦЕНКА НА ДИНАМИКАТА НА ТЕМПЕРАТУРАТА НА ЗЕМНАТА ПОВЬРХНОСТ НА ГРАД СОФИЯ С ИЗПОЛЗВАНЕ НА СПЪТНИКОВИ ДАННИ ОТ ЛАНДСАТ
}

\author{
Ив. Янев, Л. Филчев
}

\begin{abstract}
Резюме
Статията представя първи опит за анализ на градския топлинен остров на град София, използвайки спьтникови данни. За тази цел са използвани топлинните данни от сензорите ETM+ и TIRS на борда на Landsat. Направен е статистически анализ на резултатите, както и анализ на промените в температурата на повърхността за избрания времеви интервал на изследването - от 2000 до 2015 г. Анализирано е влиянието на вида земно покритие. За тази цел е съставена визуална класификация на земното покритие, при която анализираната територия е разделена на 16 класа. Подробният анализ на данните през целия период на проучването показва постепенно покачване на температурата в града поради промените в градската среда. Едно от заключенията на изследването е, че топлинните изображения могат успешно да се използват за откриване на промените в земното покритие посредством мултитемпорален анализ.
\end{abstract}

